\title{
Analyzing the impact of Technological KM and Participatory KM in FTA
}

\author{
Diego Cardoso Borda Castro ${ }^{1}$, Carlos Eduardo Barbosa ${ }^{1,2}$, Luis Felipe Coimbra Costa ${ }^{1}$, Jano Moreira de Souza ${ }^{1}$ \\ ${ }^{1} \mathrm{COPPE}$ - Graduate School and Research in Engineering \\ Universidade Federal do Rio de Janeiro (UFRJ) \\ Rio de Janeiro, Brazil \\ ${ }^{2}$ CASNAV - Center for Naval Systems Analyses \\ Brazilian Navy \\ Rio de Janeiro, Brazil
}

\{diegocbcastro, eduardo, luisfcosta, jano\}@cos.ufrj.br

\begin{abstract}
The labor market is becoming increasingly competitive, with new technologies and products being launched at all times. Companies that have the privilege of creating the products at the beginning of innovation can serve more customers and thus generate more profits. In this search for the market, companies are increasingly willing to please their customers, trying to understand what they seek. There are several concepts, ways, strategies, and technologies that help companies better understand what people are searching for, interfering with this market. These strategies include Futureoriented Technology Analysis (FTA) and others, such as Knowledge Management (KM), from which we focus on Technological and Participatory practices. These strategies are directly related bringing a fundamental advantage to the company that knows how to use these concepts effectively.
\end{abstract}

$\begin{array}{cccc}\text { Keywords } & - \text { Knowledge } & \text { Management, } & \text { Participatory } \\ \text { Knowledge } & \text { Management, } & \text { Technological } & \text { Knowledge }\end{array}$
Management, Future-oriented Technology Analysis.

\section{INTRODUCTION}

The last years have shown a growth in new ways of thinking through information technologies. With this growth, also increased the competition for the manufacture of products where companies are seeking to meet more and more the needs and expectations of their customers, leading to a race for innovation. All these transformations make companies do not know where, when and how to innovate to become more competitive ahead of their competitors.

A company needs to have a competitive intelligence to become more attractive to its consumers, knowing when to make deliver the right product at the right time. Therefore, innovating in management methods and processes is one of the main challenges of a market with fierce competition, a high degree of uncertainty and a great deal of information available.

As a possible solution to this problem, the prospection is introduced to increase the company's competitiveness, seeking to find new trends so that companies can know where they should invest. Future studies directly support decision-making at various levels in the society. The purpose is not to predict the future, but find desirable futures and ways to achieve them.

Future-oriented Technology Analysis (FTA) is an umbrella term for a wide range of activities that facilitate decisionmaking and coordinated action, especially in the formulation of science, technology and innovation policies. Understanding the changes in technologies is only a part of the understanding of the market; some other aspects can help the companies to gain their competitiveness. Among them, there are the
Technological Knowledge Management (TKM) that consists of numerous practices and use of new tools and the Participatory Knowledge Management (PKM), which involves the sharing of information through groups of people, social networks, and institutions. These strategies may be directly related, bringing advantages to the company that uses them effectively.

\section{THEORETICAL FOUNDATION}

\section{A. Future-oriented technology analysis (FTA)}

Drucker [1] states that it is not important to predict the future because it considers that it is uncertain and it is not possible to be sure of what is to happen. In contrast, Schwarz [2] argues that several managers can already understand the need to study the future for understanding what is needed.

A company must always be ahead of its competitors in technological innovations, being aware of the market's directions and prepared to face or take advantage of new technologies [3]. To make it happen, the FTA is introduced, and its importance is undeniable. However, FTA has many different concepts which are still being studied and deepened.

FTA can be defined as a set of methodologies to support decisions about emerging technologies, including their development and future impacts [4]. Therefore, several groups with different goals use a set of several approaches for the future that share some assumptions and differ in others. Their objective is to support decision-makers with analyses and new ideas to be prepared for the future [5].

\section{B. Technological Knowledge Management (TKM)}

Knowledge Management requires technologies to be done efficiently: they support strategies, processes, and methods that help to better disseminate and apply information within the enterprise. Several technologies that can help KM such as the implementation of intranets, data warehouses, data mining, decision support tools, video conferencing, groupware, electronic panels, online databases, expert systems, intelligent search agents and management of electronic documents.

TKM seeks to understand technological progress and its impacts, to enable institutions to deal with change and, above all, to integrate innovation into organizational strategy [6]. Currently, it is considered to have the most significant impact on the changes that are taking place within companies; however, although technology is widely recognized as being essential for competitiveness, technology management has been one of the most challenging activities among the attributions to managers [7]. Despite the advantages offered by

DOI reference number: 10.18293/SEKE2019-031 
technologies, some challenges are faced by companies when trying to implement them, Betz [7] cites some such as: "the not invented here syndrome", the physical separation of the research laboratories of the responsible sector, the use of inadequate techniques of planning and technological monitoring, being able to result in a distorted vision about the future and the late use of new technologies, resulting in the loss of the market for competitors [7].

\section{Participatory Knowledge Management (PKM)}

PKM is the KM derived to participatory management, which is the set of organizational conditions and managerial behaviors that encourage the participation of all in the management process. Participatory management empowers the group members to make organizational decisions [8]. Involving of everyone means that, in the beginning, no person, at any hierarchical level, should be excluded from the participatory process, everyone is aware of the methods and approaches that are being implemented within the company.

A more knowledge-oriented view can be given by Valtolina et al. [9], where they define PKM as the use of methods, tools, and guidelines to mediate cooperation between user groups and IT professionals. PKM facilitate collaboration between users who have different types of knowledge, and each user is responsible for disseminating the information. In general, PKM can be summarized as the use of a group of people to generate and use knowledge on different topics.

\section{USING TKM, PKM AND FTA IN DECISION-MAKING}

\section{A. FTA realation to PKM and TKM}

Godet [10] argues that all those who intend to foresee the future (prophets, oracles, seers, sensitives, clairvoyants, and others) are impostors because the future does not exist, it is yet to be created and therefore it is not written anywhere. In fact, talking about technological prospecting regarding knowledge can be a bit tricky as the future is uncertain and can change at any time. So how can there be statements about such? FTA seeks to assist in decision-making by looking at a history of events that may have implications for future circumstances. Logically it is not yet possible to predict the future and to know for sure what will happen, but it is possible to look at the past and the present to raise hypotheses and assumptions about some events of the future.

The junction of the FTA and KM can be seen as information-based activities, to enable an organization to anticipate its competitors and anticipate the changes that may occur, and as a consequence take advantage of that condition to increase its competitive intelligence [11]. FTA has a long-term vision and a greater focus on technology, while competitive intelligence has a short-term view with a broader discussion.

Bell and Olick [12] reformulate the idea of knowledge of the future by arguing that it is possible to postulate and think to predict some possibilities. These postulates can be seen as sets of knowledge that have to do with the consequences of situations that can evolve into a possible future.

The FTA-KM relationship is relevant since the former tries to predict future events while the latter focuses on knowledge management within the company. If the next trends are incorporated in the $\mathrm{KM}$ before they happen, they can be introduced as soon as possible in the company, bringing a competitive intelligence that aims at finding the risks and opportunities in the market early, to generate a competitive advantage. The combination of these two ideas can be seen in a very simplified way, as if FTA were to seek new knowledge and trends that can affect the market, and then enters the part of the KM that will analyze this information to manage new expertise within the company, trying to understand, store and use in the best possible way what was introduced.

As already explained, KM has some ramifications, such as TKM and PKM, and each of them relates to FTA differently, each with its particularities. The basis for the intermediation between the TKM and FTA starts at the information collection stage, which is then addressed to the treatment of them, and, finally, the systematization of the information. In other words, it is the analysis, interpretation, and production of knowledge so that, in the end, the dissemination of results is done. The TKM and PKM are interconnected and are two poles of different concepts of $\mathrm{KM}$, the former more geared towards the use of technologies and the latter for the active participation of all in an interactive way.

One of the areas of FTA that can integrate more with TKM is the technical evaluation, which seeks to predict the consequences of the introduction of a specific technology in all the spheres with which it interacts. Looking at technology management, it aims at understanding the use of tools and their impacts to enable institutions to cope with change. By reading the two concepts, it is easy to see that there is a relationship between the two, where they can help each other. With these ideas in mind, prospecting can seek new technologies that can be supported by TKM, where the former finds new concepts that can be integrated into the organization while the latter tries to manage these concepts better, trying to find better ways to apply each one of the ideas more effectively. Overall, the first aid provided by TKM for knowledge management is the use of new technologies to facilitate the exchange of information between users, increasing data speeds, assisting in connecting people of different groups.

Jaspers et al. [13] state that in the TKM, the stakes are the ways of dealing with concrete facts, for example, sites, databases, publications, dissemination procedures, among others. In this concept, forecasting processes deal with a considerable mass of information and rely primarily on systems to obtain more real and comprehensive knowledge. In this part, new technologies can help in the efficient and faster dissemination of information that has been constructed through FTA methods. On the other hand, FTA may be able to find some relevant information about the use of possible technologies, which now need to be learned and implemented within the company.

When speaking in a group of people, the first thing that comes to mind is the PKM, which has more emphasis on social practices and interactions between individuals and groups that create, develop and use knowledge, approaching the idea of the social learning cycle, taking into account cultural factors, values, and opinions. PKM includes various means of exchange and communication, such as a face-to-face meeting. 
Surveys are increasingly using the dynamics, effects of simultaneous effort/cooperation of groups and processes of dialogue to achieve new knowledge [13]. This is one of FTA main points of connection with PKM, the use, and application of information that is provided by groups of people to create new concepts within companies, linking people who are positioned in different groups.

As is the case in many other KM fields, future-oriented TKM concepts run the risk of being considered sufficient, neglecting the social side of PKM. However, a forecast is not only a process for collecting, analyzing and filtering data, and it also has a social dimension that is also very important: society needs to exchange ideas and develop visions for a collective future [13]. One of the challenges of PKM is how to efficiently use participants' knowledge and imagination to search for hypotheses for the future, by continually initiating and optimizing the interaction of information and people [13].

One of the areas of FTA that best fit with the PKM is the vision that guides the future by consensus, which uses as a base the opinions collected through the cognitive and intuitive process of a group of experts, and the PKM aims at using the mutual knowledge of a group of people. A link between these two concepts is easy to see, and the participation of groups can help create new ideas for the future.

\section{B. Proposed Approach}

As it was seen, PKM and TKM are directly related to FTA and bring several benefits to the company that correctly uses these techniques, but it is worth remembering that with these advantages they bring some harm. So, we need to know how to use them correctly. The main problems encountered were: the fear of using new technologies, the reluctance on the part of the professional to share their knowledge and the time of learning, depending on the technology presented. We seek to solve these problems creating a new concept junction model (PKM, TKM, and FTA), improving management agility, decision-making efficiency and the generation of competitive advantage.

The proposed model is presented in Fig. 1. The starting point for this methodology will be to look from the past to the present to develop a future forecast. In this method, two metrics are used: a projection based on existing data (looking at the past) and one based on queries and opinions (having something more focused on people and the present) so that, thus the future can be predicted. These two methods are being used to try to reduce the number of predicted errors and have both advantages and disadvantages. The first is a quantitative method and requires reliable and standardized historical bases, while the second is a qualitative method that presents problems with the limit of knowledge of specialists and interested people. With the two being used collaboratively, it is hoped that the problems cited will be minimized.

After the initial presentation of the methodology making use of FTA, some techniques are necessary for the forecasts to be made in the best way. Some are presented below.

- Market monitoring: used to predict possible trends, be it short, medium and long-term;

- Interviews and brainstorming: collecting participants' opinions;
- Cross-impact analysis: understanding the relationships of factors and trends found;

- Roadmaps: analysis of the technologies found;

- Creation of scenarios: considerations of plausible futures.

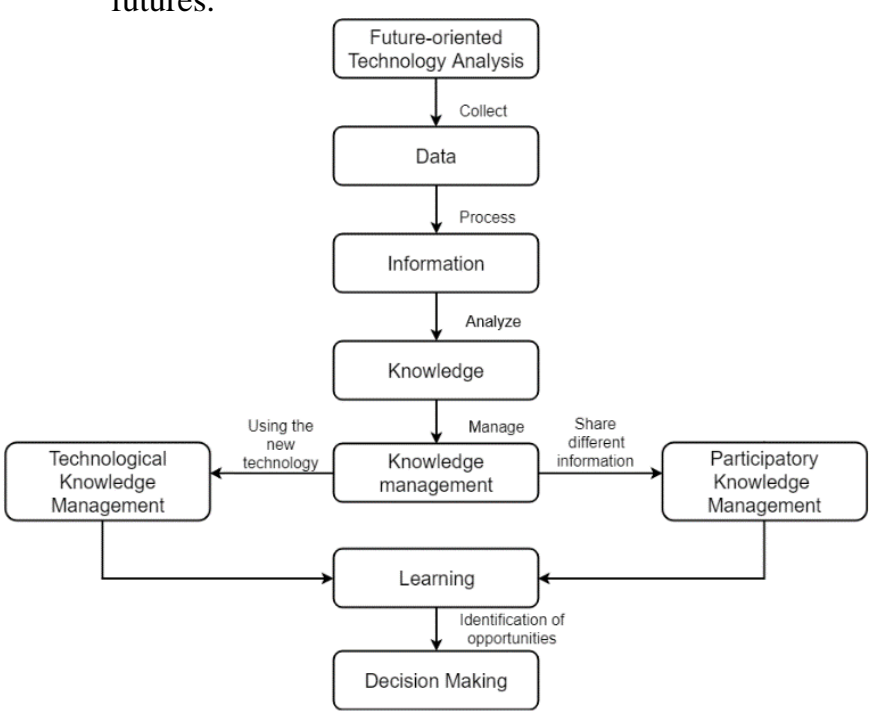

Fig. 1. Junction model with concepts of FTA, PKM, and TKM.

Five prospecting techniques have been presented, each of which has advantages and disadvantages. The use of trends offers predictive substances based on quantifiable parameters in the short term; however, at the same time, it requires historical data and thus vulnerable to change; the use of interviews and brainstorming can bring a large number of information depending on the way it is performed, yet, it is limited to the knowledge of the people who participated in the process; the analysis of cross-impacts is of great importance when a critical scenario is being developed, since it can understand the relationships between the information that has been found, but care must be taken not to obtain a biased and unreal result; the use of roadmaps seeks to implement and execute strategic maps in order to align the company's strategy with its technological capabilities, but care must also be taken in this part to avoid constructing something that cannot be accomplished; Finally, the creation of scenarios presents rich and complex portraits of possible futures, but it may bring something unattainable. Practitioners must observe which methodology best fit their context, and it is worth emphasizing that a combination of techniques is always well-seen, aiming at reducing the number of future errors. In this phase the first stage of the process ends, bringing with it the new technologies that have been recovered through prospecting. With this, many new and old data will be collected (loose data or random data without any analysis). After this collection, the data will be analyzed and thus transformed into information (organized data), and finally, this information will be converted into knowledge entering the context of the company.

With the knowledge in hand, steps in the KM. As said before, it works on the data that the company has, managing knowledge. In this approach, this management will be divided into two parts, the control of technological expertise and the participatory management of experience, each with its function. The former will try to understand the technical 
culture that was brought by FTA so that they can be introduced into the company. At this stage, two problems that have already been described are added; the fear of using new technologies and the lengthy learning time depending on the technology presented. In order to solve these two problems, four different approaches will be used: the first step will be to make a conceptualization of the employees, if they seek to understand the benefits of the technologies will be easier to accept them, as a consequence, the person will also be more willing to learn to use it. Patience, therefore, is essential in this first moment, it is necessary to explain calmly and repeat the information several times, if necessary. This first point will help the employee to accept the technology. Then, a series of training is started which can be done on the person's machine, leaving the user with the highest possible tranquility. On the other hand, faceto-face training will also be carried out, where the person can take his most recurring questions to be clarified with specialized professionals in the field. In the third stage, the concept of pair programming will be used with another view, where some jobs with different levels of difficulty will be advised to various people who have done the training, always seeking to leave a more experienced person with a less skilled one. In the fourth and final phase, it will be suggested that people who have never performed a particular task can try, to be able to learn more about the work and, consequently, decrease the dependency of specialists in a specific area within the company. This last proposal would help the employees to create, in turn, a desire to seek new knowledge, because only then would they be able to deliver the task

Once the TKM issues have been resolved, PKM is introduced so that people from many different knowledgeable areas can share their information in a unified way. The main idea is everyone would participate equally in this step, being able to collaborate with what they judge necessary, completely altering the organizational climate, where all employees would be like "leaders" having a self-management, stimulating, guiding and coordinating changes. This model is very flexible and aims at leveling the group, boosting participation and dismembering the traditional model. For this model to be deployed correctly, two points must be aligned within the company. The first one is the need for communication between the sectors to make information exchange possible. The second is that a friendly working environment is necessary, where everyone can be allowed to speak equally.

In the PKM stage, a new problem is presented, the reluctance on the part of the professional in sharing their knowledge. In the search for the solution of this problem, some ways of exchanging information will be presented. The first is to create an intranet so that employees can register what they find relevant. The second is to create a bank of ideas to encourage employees to adopt a creative attitude. Awards would be given to the ideas that were judged more pertinent, promoting a friendly competition among the participants. The last thought would be the creation of study groups within the company, where groups with specific themes would be created, each week a different group would talk about what they have learned over time, thus spreading the information in another way. The groups would be formed with a fixed time, so that people are always participating in different groups at all times, sharing what they learned. This completes the stages of the search, analysis, knowledge generation and conceptualization. Learning in this scheme can be seen as an extension of the idea of experience, i.e., people will do with everything they have understood and learned. They know how to use the knowledge in the right way, identifying what is the best decision to make.

\section{FINAL REMARKS}

The market is increasingly competitive with new creations. For a company to win its market, it must have an advantage over the others. In this quest for advantages, technological prospecting methods are being used so that it is possible to create visions of the future and thereby to know what are the new preferences and trends of this market. In this search for new technologies, FTA can benefit from several methods to try to predict the future, such as the use of road mapping, expert opinion, trend monitoring, among many others.

Once this new information has been retrieved and stored, it needs to be handled and managed for better use. At that time the part of the KM enters, seeking to manage this data the best way. For this to happen effectively, KM was branched out in two areas to PKM and TKM, each with its primary focus.

In this work, we presented a brief explanation about the aspects of FTA, TKM, and PKM, after the necessary reports have been made, a search on what has already been done to improve this area was carried out, and finally a new approach of utilization of these three concepts. As future work we intended to test it in an organization to confirm its viability.

\section{REFERENCES}

[1] P. F. Drucker, The Essential Drucker. HarperCollins, 2001.

[2] J. Oliver Schwarz, "Assessing the future of futures studies in management," Futures, vol. 40, no. 3, pp. 237-246, Apr. 2008.

[3] D. Reis and R. Lobo, "Technological forecasting: the methodology used by a federation of industries in Brazil," Australian Journal of Basic and Applied Sciences, vol. 9, no. 20, pp. 503-509, 2015.

[4] A. L. Porter et al., "Technology futures analysis: Toward integration of the field and new methods," Technological Forecasting and Social Change, vol. 71, no. 3, pp. 287-303, Mar. 2004.

[5] C. Cagnin, A. Havas, and O. Saritas, "Future-oriented technology analysis: Its potential to address disruptive transformations," Technological Forecasting and Social Change, vol. 80, no. 3, pp. 379385, 2013.

[6] R. SBRAGIA, "Apresentação do XXI Simpósio de Gestão da Inovação Tecnológica," São Paulo: USP/FEA, 2000.

[7] F. Betz, "Strategic technology management," 1993.

[8] A. Bernardes, G. G. Cummings, C. S. Gabriel, Y. D. M. Évora, V. G. Maziero, and G. Coleman-Miller, "Implementation of a participatory management model: analysis from a political perspective," Journal of Nursing Management, vol. 23, no. 7, pp. 888-897, 2015.

[9] S. Valtolina, B. R. Barricelli, and Y. Dittrich, "Participatory knowledgemanagement design: A semiotic approach," Journal of Visual Languages \& Computing, vol. 23, no. 2, pp. 103-115, Apr. 2012.

[10] M. Godet, "Caixa de Ferramentas da prospectiva tecnológica," Centro de Estudos de Prospectiva e Estratégia-CEPES, Lisboa, 2000.

[11]A. Eerola and I. Miles, "Methods and tools contributing to FTA: A knowledge-based perspective," Futures, vol. 43, no. 3, pp. 265-278, Apr. 2011 .

[12]W. Bell and J. K. Olick, "An epistemology for the futures field: Problems and possibilities of prediction," Futures, vol. 21, no. 2, pp. 115-135, Apr. 1989.

[13]M. Jaspers, H. Banthien, and J. Mayer-Ries, "New forms of knowledge management in participatory foresight: The case of 'Futur,"' in Eu-us seminar: New technology foresight, forecasting \& assessment methods (Seville, 2004. 